\title{
Recording from a Single Motor Unit During Strong Effort
}

\section{Andreassen, Steen; Rosenfalck, Annelise}

Published in:

I E E E Transactions on Biomedical Engineering

Link to article, DOI:

10.1109/TBME.1978.326283

Publication date:

1978

Document Version

Publisher's PDF, also known as Version of record

Link back to DTU Orbit

Citation (APA):

Andreassen, S., \& Rosenfalck, A. (1978). Recording from a Single Motor Unit During Strong Effort. I E E E Transactions on Biomedical Engineering, 25(6), 501-508. https://doi.org/10.1109/TBME.1978.326283

\section{General rights}

Copyright and moral rights for the publications made accessible in the public portal are retained by the authors and/or other copyright owners and it is a condition of accessing publications that users recognise and abide by the legal requirements associated with these rights.

- Users may download and print one copy of any publication from the public portal for the purpose of private study or research.

- You may not further distribute the material or use it for any profit-making activity or commercial gain

- You may freely distribute the URL identifying the publication in the public portal 


\title{
Recording from a Single Motor Unit During Strong Effort
}

\author{
STEEN ANDREASSEN AND ANNELISE ROSENFALCK
}

\begin{abstract}
During strong voluntary effort it is rarely possible to identify the action potentials from single motor units. In large muscles the most selective recordings are obtained with bipolar wire electrodes. To elucidate this experimental finding we have calculated the extracellular field around a single muscle fiber from an intracellular muscle action potential. This model showed that the selectivity of a bipolar electrode is high provided:

i) the diameter of the recording surfaces is less than half the diameter of the muscle fibers;

ii) the center distance between the recording surfaces is of the same order or smaller than the diameter of the muscle fibers, and when

iii) the center-line between the recording surfaces is oriented perpendicular to the direction of the muscle fibers.

A bipolar electrode with these properties will give a maximal attenuation of the field from distant muscle fibers and only two to nine fibers close to the electrode contribute to the recording.

Action potentials were recorded from the anterior tibial muscle of normal subjects with a trifilar cut end electrode and a bifilar side hole electrode. The recording surfaces of the side hole electrode can be positioned close to active muscle fibers by gently pulling the electrode at either side of the muscle.

The recording surfaces should not be smaller than $25 \mu \mathrm{m}$. Otherwise the impedances of the recording surfaces are so large that the capacitance between wire and muscle tissue degrades the selectivity of the electrode. Improving selectivity by high-pass filtering was avoided. Narrowing the frequency band made action potentials from different motor units appear similar in shape, thereby making identification more difficult.

The amplitudes and the power spectra of action potentials recorded with these electrodes were in accordance with the model and no more than one to three motor units were present up to $60 \%$ of maximal effort.
\end{abstract}

\section{INTRODUCTION}

$\mathrm{T}$ HE STUDY of interval patterns of single motor units requires that each action potential throughout a recording period of several seconds can be identified. Bipolar electrodes are best suited for single unit recording from large muscles because they pick up the potentials from the fibers which lie close to the electrodes and attenuate the potentials of distant fibers. During strong voluntary effort it is rarely possible to obtain recordings in which one motor unit is clearly visible without interference from other units [1]-[8]. To clarify whether recording conditions can be improved we have calcu-

Manuscript received June 21, 1977; revised November 29, 1977. This work was supported by the Danish Council for Scientific and Industrial Research and by the Danish Medical Research Council.

S. Andreassen was with the Electronics Laboratory, Technical University of Denmark and with the Institute of Neurophysiology, University of Copenhagen, Copenhagen, Denmark. He is now with the Institute of Electronic Systems, Aalborg University Centre, Aalborg, Denmark.

A. Rosenfalck was with the Institute of Neurophysiology, University of Copenhagen, Copenhagen, Denmark. She is now with the Institute of Electronic Systems, Aalborg University Centre, Aalborg, Denmark. lated the potentials from muscle fibers as they would be recorded by unipolar and bipolar electrodes of different dimensions. The extracellular field around a muscle fiber surrounded by an anisotropic conductor was calculated from the intracellular potential according to P. Rosenfalck [9]-[12]. On the basis of this model, we have selected the parameters for two different bipolar electrodes. Finally we have tested the model by recording with the electrodes from the anterior tibial muscle in man.

\section{MODELING}

The properties of a bipolar electrode depend on three factors: i) the orientation of the recording surfaces relative to the direction of the muscle fibers, ii) the distance between the recording surfaces, and iii) the areas of the recording surfaces.

To investigate the dependence on these factors we calculated the extracellular field around a muscle fiber in situ. The extracellular potential field was calculated by means of a method suggested by P. Rosenfalck [9] -[12] from an intracellular action potential measured by Ludin [13]. The model takes into account the radius and conduction velocity of the muscle fiber, the anisotropy of muscle tissue, i.e., the difference in conductivity parallel to the fiber direction and perpendicular to it, and the conductivities of the intracellular and extracellular medium (see Appendix).

A unipolar electrode with point-shaped recording surface will record the potential around the fiber. The potential recorded with a bipolar electrode was calculated as the difference in potential between two nearby points. Potentials were calculated for bipolar electrodes lying parallel and perpendicular to the muscle fiber (Fig. 1). If the two recording surfaces have the same distance to the muscle fiber the signal is extinguished (equidistant, Fig. 1).

Potentials were calculated at different distances from a muscle fiber for unipolar electrodes and for bipolar electrodes with a center distance between the recording surfaces of $25 \mu \mathrm{m}$ (Fig. 2 left).

\section{RESULTS}

In unipolar recording the peak-to-peak amplitude is $1260 \mu \mathrm{V}$ at distance 0 from the muscle fiber. In bipolar perpendicular recording the potential can be extinguished if the recording surfaces have the same distance to the fiber (equidistant, Fig. 1). With one recording surface at the fiber and the other at distance $25 \mu \mathrm{m}$ the amplitude is $30 \%$ of the potential recorded unipolarly. When the center-line of the bipolar electrode is parallel to the fiber axis the peak-to-peak amplitude is less than $10 \%$ of the amplitude in unipolar recording.

With larger center distances $(c)$ between the recording sur- 


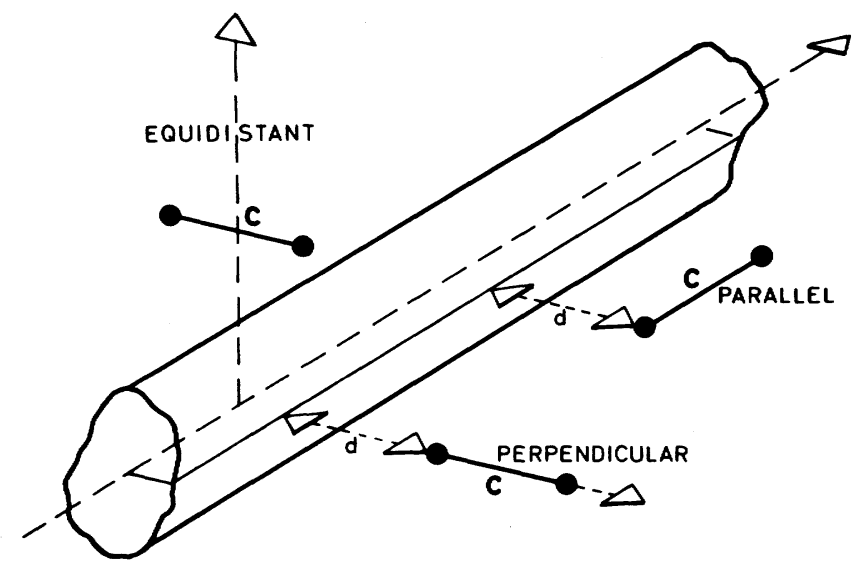

Fig. 1. The two recording surfaces of bipolar electrodes placed relative to the muscle fiber in two orthogonal directions: parallel and perpendicular. $d$ is the distance from the surface of the muscle fiber to the nearest recording surface, and $c$ is the center distance between the two recording surfaces.

faces the amplitudes are greater, the increase being about proportional to the center distance when the center-line is parallel to the fiber direction and less steep when it is perpendicular to it (Table 1).

For increasing distance between muscle fiber and electrodes the peak-to-peak amplitude decreases (Fig. 2). To estimate the decline in amplitude as a function of distance between the surface of the fiber and the electrodes, the data are expressed in percent of the maximal amplitude recorded with the electrodes at distance 0 (Fig. 3). The distance at which the amplitude has declined to $25 \%$ (25\%-distance) is $116 \mu \mathrm{m}$ with unipolar recording. With bipolar recording the $25 \%$-distance is 63 and $76 \mu \mathrm{m}$ when the electrode is perpendicular and parallel to the fiber direction. The decline in amplitude is two to three times greater for bipolar than for monopolar recording at a distance of $200 \mu \mathrm{m}$ and three to five times at $500 \mu \mathrm{m}$. This explains that bipolar electrodes are selective because distant fibers contribute less to the signal in bipolar than in unipolar recording.

The number of fibers which contribute to the signal at maximal effort was estimated by placing a drawing of the pick-up ranges of an electrode with the recording surfaces embedded in a wall of insulating material over a micrograph of the crosssection of an anterior tibial muscle (Fig. 4). The pick-up range is the region within which the center of a muscle fiber should lie if the potential picked up by the electrode should be greater than $25 \%$ of the potential from a fiber close to the electrode. With unipolar recording the pick-up range is a semicircle with a radius of $144 \mu \mathrm{m}$ (fiber radius: $28 \mu \mathrm{m}$ plus the $25 \%$-distance: $116 \mu \mathrm{m}$, Fig. 3). With two recording surfaces placed along the muscle fiber (bipolar, parallel electrode) the pick-up range was $104 \mu \mathrm{m}(28 \mu \mathrm{m}+76 \mu \mathrm{m})$. When the two recording surfaces were placed perpendicular to the fibers the pick-up range was considerably smaller because fibers which lie "equidistant" to the recording surfaces do not contribute to the signal. By moving the drawing to different positions over the micrograph the number of fibers within the pick-up ranges were counted as nine to seventeen in unipolar, five to nine in bipolar parallel recording and two to seven in bipolar perpendicular recording.

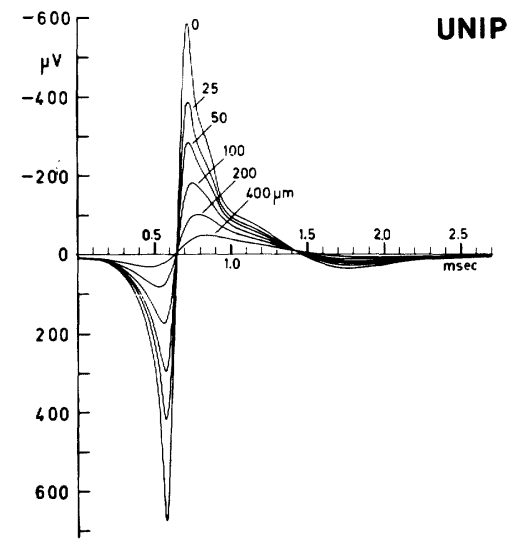

UNIPOLAR
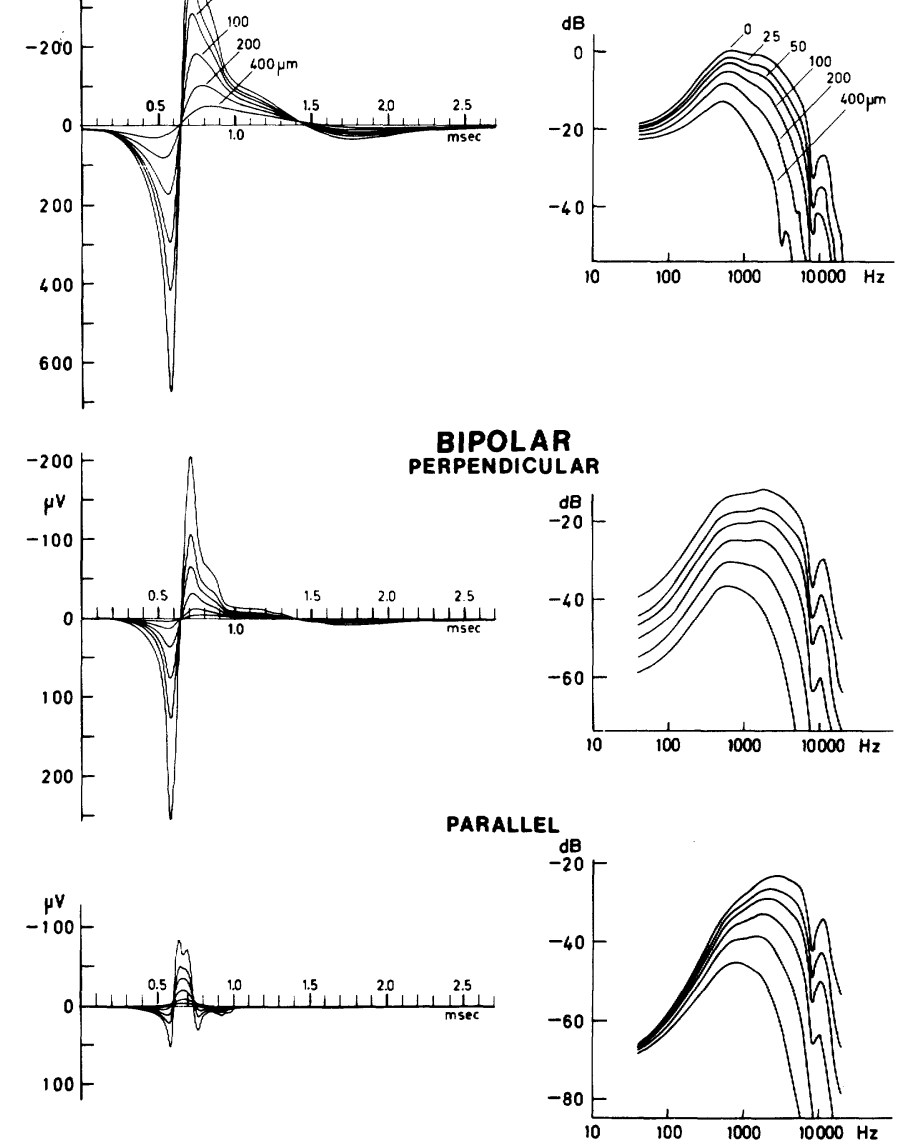

Fig. 2. Left: Action potentials at different distances $(d: 0 \mu \mathrm{m}, 25 \mu \mathrm{m}$, $50 \mu \mathrm{m}, 100 \mu \mathrm{m}, 200 \mu \mathrm{m}$ and $400 \mu \mathrm{m}$ ) from a muscle fiber computed from the intracellular action potential for a unipolar electrode (above), for a bipolar electrode with the recording surfaces perpendicular to the fiber axis (middle) and for a bipolar electrode with the recording surfaces parallel to the fiber axis (below). Right: Action potentials at different distances from a muscle fiber converted to the frequency domain by a Fast Fourier Transform. $0 \mathrm{~dB}=$ maximal value of power spectrum for the potential recorded unipolarly at distance 0 from the fiber surface.

TABLE 1

Number of Fibers $(n)$ Within the Pick-up Range of Unipolar and Bipolar Electrodes, Compared to the Peak-to-Peak Amplitudes

( $A$ ) of Action Potentials from a Muscle Fiber Close to the Electrodes for InCreasing Distance $(c)$ Between the RECORDING SURFACES

\begin{tabular}{|cc|cc|c|cc|}
\hline unipolar & \multicolumn{2}{|c|}{$\begin{array}{c}\text { bipolar } \\
\text { perpendicular }\end{array}$} & & parallel \\
\hline $\mathrm{n}$ & A $\mu \mathrm{V}$ & $\mathrm{n}$ & A $\mu \mathrm{V}$ & $\mathrm{c} \mu \mathrm{m}$ & $\mathrm{n}$ & A $\mu \mathrm{V}$ \\
\hline \multirow{3}{*}{$9-17$} & \multirow{3}{*}{1260} & $2-7$ & 460 & 25 & & 140 \\
& & $2-9$ & 690 & 50 & $5-9$ & 250 \\
& & $4-11$ & 900 & 100 & & 490 \\
& $>15$ & 1100 & 200 & & 900 \\
\hline
\end{tabular}

The bipolar electrode with recording surfaces placed perpendicular to the fiber direction is thus highly selective when the center distance between the recording surfaces is $25 \mu \mathrm{m}$. With a center distance of $50 \mu \mathrm{m}$ the electrode could still be placed 


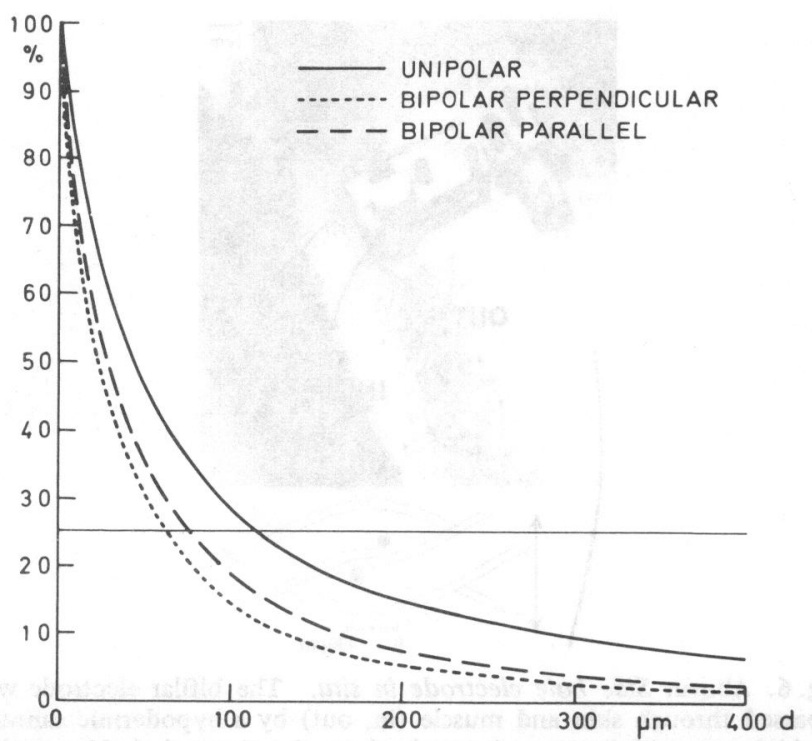

Fig. 3. Decline in peak-to-peak amplitude of the action potential calculated from Fig. 2 for a unipolar electrode and for bipolar electrodes placed perpendicular or parallel to the direction of the muscle fibers. Ordinate: Amplitude in per cent of amplitude at distance 0 from the fiber surface. Abscissa: Distance $d$ from fiber surface to the nearest recording surface (see Fig. 1). The distance at which the amplitude has declined to $25 \%$ (25\%-distance) is determined for the three electrodes by the horizontal line (unipolar $116 \mu \mathrm{m}$, bipolar perpendicular $63 \mu \mathrm{m}$, bipolar parallel $76 \mu \mathrm{m})$.

such that only two fibers may contribute to the signal but in other positions up to nine fibers may contribute (Table 1). With a center distance of $100 \mu \mathrm{m}$ the number of fibers within the pick-up range is four to eleven. With center distances greater than $200 \mu \mathrm{m}$ the pick-up range will be similar to that of two monopolar electrodes. When the bipolar electrode is placed parallel to the fiber direction the pick-up range is independent of the distance between the recording surfaces.

It therefore seems possible to record from few fibers with a bipolar electrode provided the center-line is perpendicular to the fiber axis and the center distance is less than $50 \mu \mathrm{m}$. If the center-line is at an angle to the fiber direction the electrode will act as a perpendicular electrode as long as the angle is less than $45^{\circ}$. This is because the perpendicular component of the field at center distances less than $50 \mu \mathrm{m}$ is three to four times greater than the parallel component of the field (Table 1).

It was assumed in the modeling that the recording surfaces were point-shaped. The calculations are, however, also valid for the $25 \mu \mathrm{m}$ recording surfaces used in most single fiber electrodes. Using a simpler "tripole" model Ekstedt and Stålberg [14] have shown that recording surfaces which are $25 \mu \mathrm{m}$ or smaller only slightly decrease the action potential in comparison to recording with point-shaped surfaces.

The shape of the potentials from single muscle fibers depends on the electrode, the duration of the spike being shorter (0.4-0.6 $\mathrm{ms})$ in bipolar than in unipolar recording $(1.0 \mathrm{~ms})$. This is important when several motor units are present in a recording because fewer potentials superimpose and each potential from the individual units can thus better be identified.

A quantitative expression for the change in shape with increasing distance between the muscle fiber and the three electrode types is obtained by converting the action potentials in

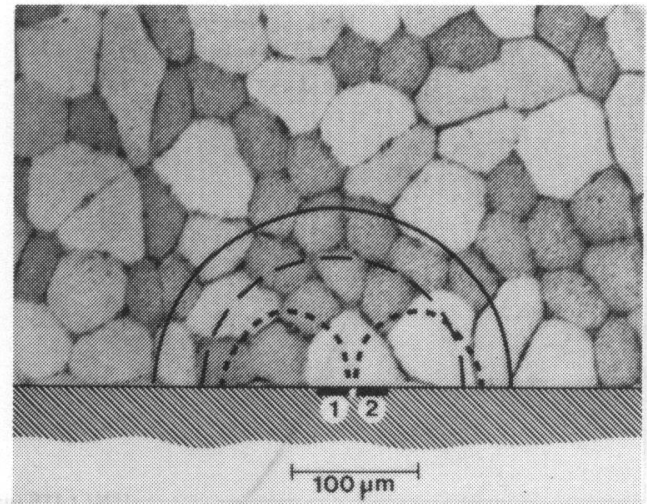

Fig. 4. Pick-up ranges for i) a unipolar electrode (full semicircle) with recording surface at position 1 ; ii) a bipolar perpendicular electrode (dotted line with two lobes) with recording surfaces at positions 1 and 2; and iii) a bipolar parallel electrode (dotted semicircle) with recording surfaces at position 1 and $25 \mu \mathrm{m}$ above (or below) position 1. The recording surfaces are embedded in a wall of non-conducting material. The pick-up ranges are superimposed on a micrograph from an anterior tibial muscle in man (courtesy of Dr. Schmalbruch). At various positions on the micrograph the numbers of fibers within the pick-up ranges are nine to seventeen for the unipolar electrode, two to seven for the bipolar perpendicular electrode and five to nine for the bipolar parallel electrode.

Fig. 2 left to the frequency domain by a "Fast Fourier Transform" (Fig. 2 right). For zero distance between electrode and fiber surface peak in the power spectrum is at $0.8 \mathrm{kHz}$ for unipolar, at $2.8 \mathrm{kHz}$ for bipolar parallel and at $1.8 \mathrm{kHz}$ for bipolar perpendicular recording. With increasing distance between electrode and fiber the peak moves towards lower frequencies. Note that the upper limiting frequency of the amplifiers and recording equipment should be $7 \mathrm{kHz}$ or better to avoid reduction of the amplitude of the spike potentials from single fibers. From the power spectra the $25 \%$-distances can be calculated as a function of frequency (Fig. 5). The 25\%-distance in bipolar perpendicular recording is less than $110 \mu \mathrm{m}$ through the frequency range, which means that the selectivity is good for all frequencies. This also implies that for the bipolar perpendicular electrode configuration only minor improvements can be obtained by filtering.

\section{Electrode DesignS}

We have used two different wire electrodes, one with side holes and another in which the recording surfaces are the cut ends of the wire.

The side hole electrode consisted of two $75 \mu \mathrm{m}$ stainless steel wires insulated by Teflon and twisted. The recording surfaces were two holes $(10-25 \mu \mathrm{m})$ burned into the side of the wire by an induction coil [15], [16].

The side holes were positioned at an angle of $45^{\circ}$ to the direction of the wires such that the distance between the recording surfaces perpendicular and parallel to the fiber direction was approximately $50 \mu \mathrm{m}$ (Fig. 6).

The electrode was inserted by a curved hypodermic cannula which was passed through skin and muscle. The electrode was then pushed forward and the cannula withdrawn (Fig. 6). The recording surfaces were moved close to active muscle fibers by gently pulling on either end of the wire. It could also be 


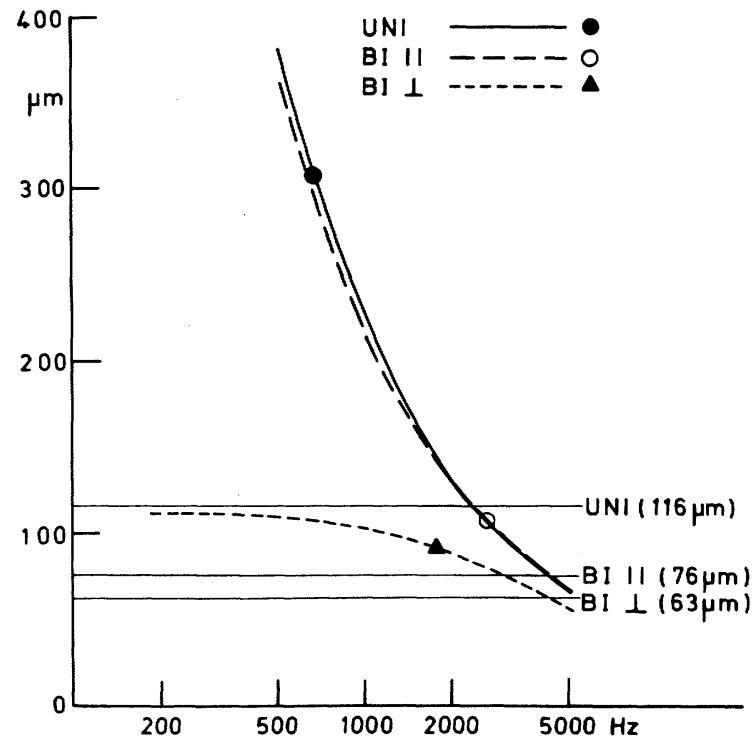

Fig. 5. The 25\%-distances for unipolar, bipolar parallel (BI $\|$ ) and for bipolar perpendicular (BI $\perp$ ) recording as a function of frequency. The distances were calculated from the power spectra (Fig. 2 right). The horizontal lines indicate the $25 \%$-distance for the peak-to-peak amplitudes of the action potentials as determined in Fig. 3. The peaks in the power spectra are indicated by dots ( $\bullet$ unipolar: $0.8 \mathrm{kHz}$, o bipolar parallel: $2.8 \mathrm{kHz}$, and $\Delta$ bipolar perpendicular: $1.8 \mathrm{kHz}$ ).

moved to other positions for further investigations of other motor units.

The cut end electrode consisted of three insulated stainless steel wires, $25 \mu \mathrm{m}$ in diameter, twisted and glued together with araldite (Fig. 7). The electrode was bent to form a hook and the wire ends were the recording surfaces. The electrode was inserted by a hypodermic needle, which was withdrawn. The orientation of the recording surfaces relative to the fiber direction was random. The action potentials were recorded between the two surfaces which gave single unit responses at the highest level of contraction. According to the model this will be the surfaces which lie perpendicular to the fiber direction. During the first contraction after the electrode was placed into the muscle $5-10 \mathrm{~mm}$ of the wire was drawn into the muscle. This "slack" helps the recording surfaces to remain close to the same muscle fiber during contraction. However, once inserted the electrode can only be moved slightly by pressing at the surface of the muscle.

Electrode holder (Fig. 6): For both electrodes the thin wires were attached to springs [17]. The cannula used for insertion of the wires was withdrawn and remained on the electrode holder during recording. The holder with the electrode in the cannula was sterilized in boiling water.

\section{Electrode Properties}

\section{Electrical Properties}

The improvement in selectivity obtained by bipolar perpendicular electrodes relies in part on the shape of the pick-up area, where fibers lying close to the mid-line (Fig. 4) do not give rise to any potential. This only applies if the bipolar electrode records potential difference, or in other words if the electrode preamplifier configuration has a high Common Mode Rejection (CMR). Considering the magnitudes of the unipolar and bipolar potentials (Fig. 2) the CMR should be greater than

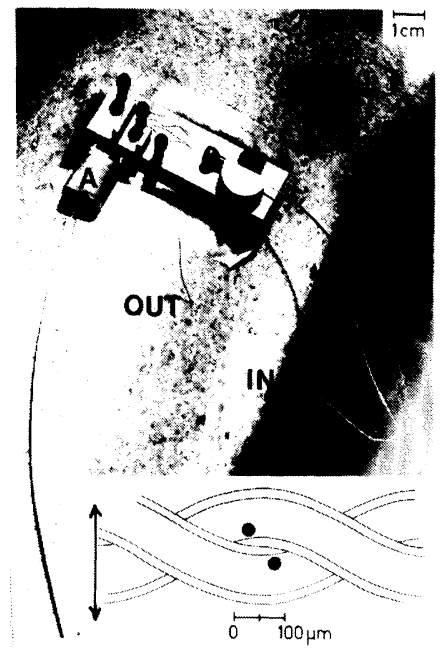

Fig. 6. Above: Side hole electrode in situ. The bifilar electrode was passed through skin and muscle (in, out) by a hypodermic cannula which was withdrawn and remained on the electrode holder during the recording period. The wires were $75 \mu \mathrm{m}$ stainless steel insulated by Teflon. Below: The recording surfaces were positioned at an angle of $45^{\circ}$ to the direction of the muscle fibers (arrow). The center distance perpendicular to the fiber direction was about $50 \mu \mathrm{m}$. The wires were fixed to springs on the electrode holder and the input amplifier (A) was plugged directly to these springs. The holder with the springs was sterilized in boiling water.

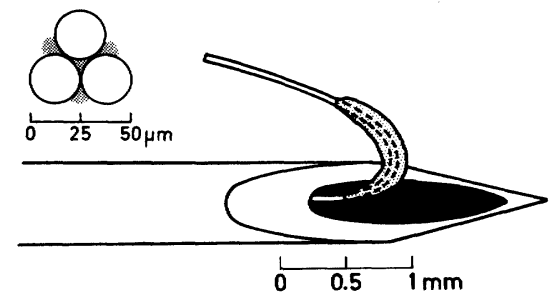

Fig. 7. The cut end electrode was bent to form a hook. It consisted of three $25 \mu \mathrm{m}$ stainless steel wires insulated by enamel and held together by araldite. The hook was reinforced by araldite to avoid damaging the enamel during insertion of the electrode. Above left: the cut ends of the wires.

ten throughout the frequency range $20 \mathrm{~Hz}-10 \mathrm{kHz}$. We measured the parameters that determine CMR, i.e., impedance of the electrode surfaces, capacitance between the electrode wires and the tissue and the preamplifier input impedance (Table 2).

The impedances of the recording surfaces are mainly resistive at frequencies above $1 \mathrm{kHz}$. They were measured at $3-5 \mathrm{kHz}$ in $0.15 \% \mathrm{NaCl}$ with a test signal of $1 \mathrm{mV}$. The impedances of the holes which were burned into the side of the Teflon wire were $160 \mathrm{k} \Omega / 200 \mathrm{k} \Omega$ in one electrode and $400 \mathrm{k} \Omega / 700 \mathrm{k} \Omega$ in another. For the cut end electrode the impedances were more similar, $380 \mathrm{k} \Omega / 400 \mathrm{k} \Omega$. The impedances were kept low by passing a current $1-10 \mu \mathrm{A}(1-10 \mathrm{~s})$ through them after they were sterilized. The procedure could be repeated with the electrodes in situ if necessary.

The capacitance between the wires and the tissue depends on the thickness and material of the insulation. The side hole electrode was Teflon insulated $(2.4 \mathrm{pF} / \mathrm{cm})$ and the cut end electrode enamelled $(12.5 \mathrm{pF} / \mathrm{cm})$. When $5 \mathrm{~cm}$ of the wires lie in the muscle the capacitances are $12 \mathrm{pF}$ and $60 \mathrm{pF}$ respectively.

The preamplifier was an FET source follower. It was connected directly to the springs on the electrode holder (Fig. 6) to avoid the effect of the capacitances of a shielded input 
TABLE 2

IMPEDANCE OF ReCORDING SURFACES $(R)$, CAPACITANCE OF THE INPUT Circuit $(C g)$ and the Resulting Common Mode Rejection (CMR) OF THE INPUT CIRCUIT

\begin{tabular}{c|c|c|c}
\hline & \multicolumn{2}{|c|}{ Side hole electrode } & Cut end electrode \\
\hline$R_{1} / R_{2} \mathrm{k} \Omega$ & $160 / 200$ & $400 / 700$ & $380 / 400$ \\
$\mathrm{Cg} \mathrm{pF}$ & 20 & 20 & 70 \\
$\mathrm{CMR}$ & $>33(20-10,000 \mathrm{~Hz})$ & $\begin{array}{c}50(100 \mathrm{~Hz}) \\
8(1,000 \mathrm{~Hz}) \\
3(3-10 \mathrm{kHz})\end{array}$ & $>25(20-10,000 \mathrm{~Hz})$ \\
\hline
\end{tabular}

$R_{1}$ and $R_{2}$ are the resistive components of the impedances of the two recording surfaces measured at $3-5 \mathrm{kHz}$ in $0.15 \% \mathrm{NaCl}$ solution $(1 \mathrm{mV})$. $\mathrm{Cg}$ is the sum of the capacitance between the wires and the muscle and the input capacitance of the preamplifier to ground $(<10 \mathrm{pF})$.

cable which might be of the order of $100 \mathrm{pF}$. The input impedance was more than $1 \mathrm{G} \Omega$ and the capacitance to ground less than $10 \mathrm{pF}$.

The Common Mode Rejection (CMR) was measured by applying a common signal to the recording surfaces in $0.15 \%$ $\mathrm{NaCl}$. Only $2 \mathrm{~mm}$ of the wires around the recording surfaces were dipped. The capacitances between the wires and the tissue were simulated in two ways: i) by connecting two capacitances between the input leads of the preamplifier and ground, or ii) by dipping $5 \mathrm{~cm}$ of the wires in a second bath connected to ground. For the cut end electrode less than $4 \%$ of the common signal was transferred to the amplifier terminals as a difference signal (CMR > 25). For the side hole electrode with low impedances $(160 \mathrm{k} \Omega / 200 \mathrm{k} \Omega)$ the CMR was greater than 33 . For the side hole electrode with high impedances $(400$ $\mathrm{k} \Omega / 700 \mathrm{k} \Omega$ ) the CMR decreased inversely proportional to the frequency and reached a level of three at $3 \mathrm{kHz}$. These measurements of CMR agree with values calculated from the measured values of electrode impedances and wire and amplifier capacitances.

The conclusion from these results is that due to small differences in impedances of the recording surfaces CMR is sufficiently great for the cut end electrode, in spite of the large capacitances. The side hole electrode has smaller capacitances, but a much greater difference between the impedances of the recording surfaces. A calculation shows that the difference in impedances should be kept below $100 \mathrm{k} \Omega$ for the side hole electrode to obtain a CMR greater than ten throughout the frequency range from $20-10,000 \mathrm{~Hz}$. However, since the capacitance between wire and tissue remains constant during the recording period, it may be possible to avoid its limiting effect by using a negative capacitance differential preamplifier.

\section{Selectivity}

Action potentials from single motor units were recorded during constant voluntary contraction of the anterior tibial muscle. The force was measured as torque at the ankle. With the side hole electrode clear recordings from single motor units were obtained at $20-30 \%$ of maximal effort over periods of several minutes (Fig. 8). Potentials from one to three motor units could be identified up to $60 \%$ of maximal effort. At the highest levels of contraction only few records were stable over more than $30 \mathrm{~s}$. When the side holes were more than $50 \mu \mathrm{m}$ apart the selectivity was much less. In recordings with a multielectrode, Gath and Stålberg [8] found the optimal distance

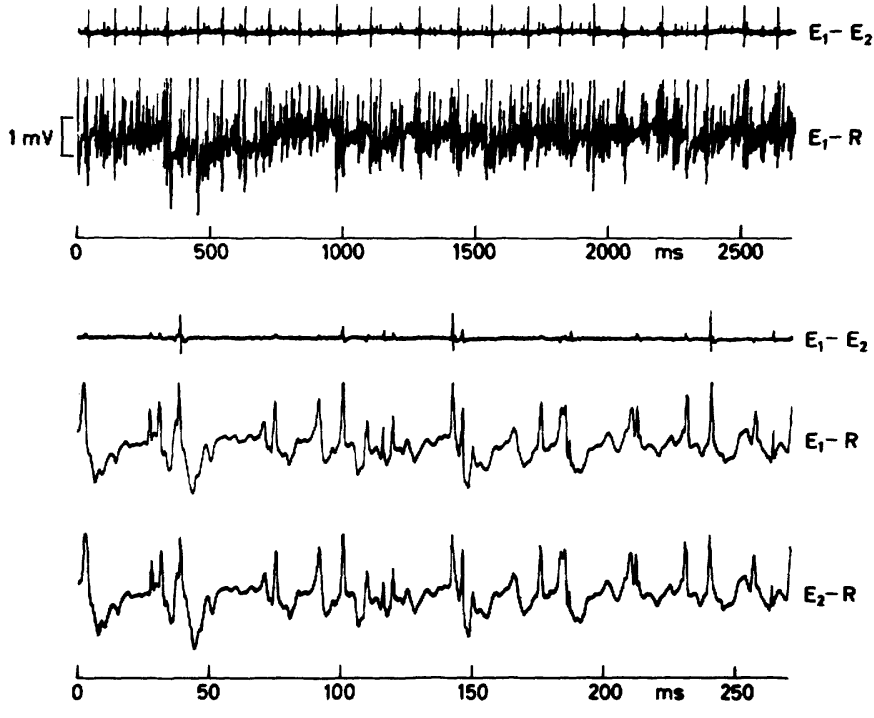

Fig. 8. Clearly visible single-unit potentials recorded bipolarly $\left(E_{1}-E_{2}\right)$ by a side hole electrode from the anterior tibial muscle at $30 \%$ of maximal effort. Upper trace: at low time resolution, third trace: the initial $250 \mathrm{~ms}$ at a ten times higher time resolution. The level of activity is illustrated in the other traces recorded between either of the two side holes $\left(E_{1}\right.$ and $\left.E_{2}\right)$ and a large reference electrode $(R)$ placed subcutaneously.

between the recording surfaces to be $140 \mu \mathrm{m}$. Using $60 \mu \mathrm{m}$ their recording was slightly more selective but very sensitive to electrode movements. Cut end wire electrodes follow the movements of the muscle and can thus stay close to the same muscle fibers at higher levels of contraction. The cut end electrode was very selective and we had the same experience as Clamann and Lamb [7]: in many instances no activity could be obtained in normals at low contraction levels. Recordings from single motor units were obtained up to $60 \%$ of maximal effort in normals.

These findings agree with the model. In both electrodes the component of the center distance perpendicular to the fiber direction was less than $50 \mu \mathrm{m}$ and only two to nine fibers are then within the pick-up range of the electrode.

From studies of the fine structure of the motor unit in man it is known that fibers from fifteen to thirty motor units lie intermingled in the larger muscles in man (for review see [18] and [19]). In rat and cat muscle most fibers belonging to the same motor unit lie solitary [20], [21]. Electrophysiological evidence suggests that the fibers of a motor unit also lie scattered in man [22]. In that case about $20 \%$ of the two to nine fibers within the pick-up range of the bipolar perpendicular electrode belong to the same motor unit. This illustrates that only in some instances it was possible to record from single motor units at maximal effort as reported by Bigland and Lippold [1], Norris and Gasteiger [2] and Hannerz [5].

\section{Spectra and Amplitudes of Recorded Potentials}

The action potentials were similar in shape and duration to the potentials calculated by the model and there was agreement between power spectra computed from the recorded potentials and determined by the model (Figs. 9 and 2).

The amplitudes of the action potentials ranged from $100 \mu \mathrm{V}$ to $8 \mathrm{mV}$. With the side hole electrode the median amplitude was $800 \mu \mathrm{V}$, two times greater than when recorded with the 

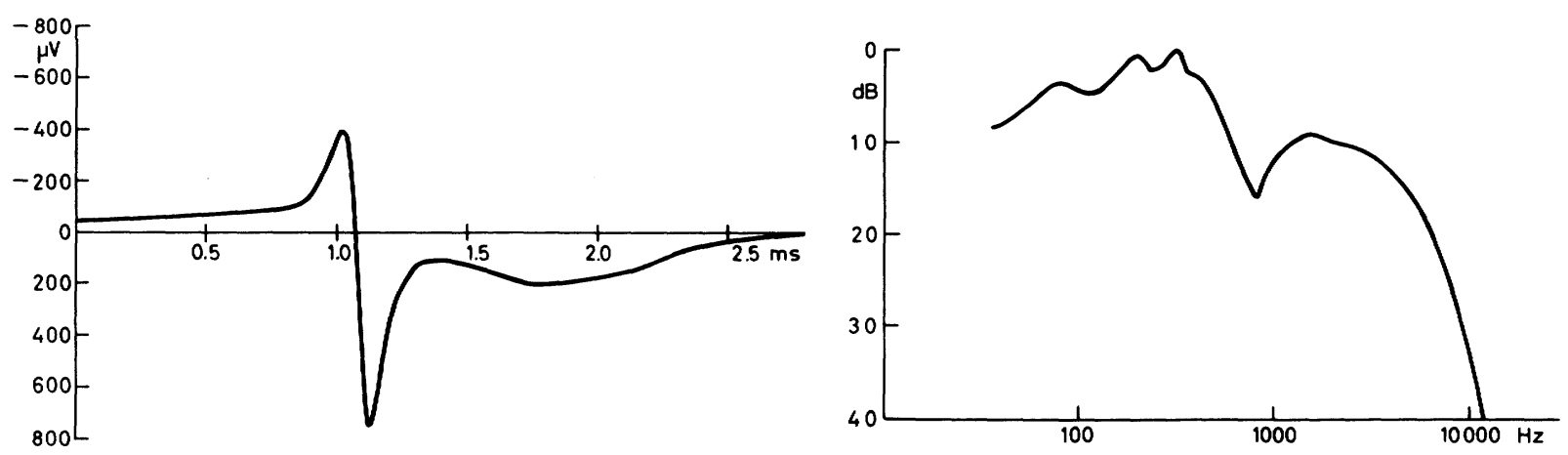

Fig. 9. Action potential recorded by a side hole electrode (left) and its power spectrum (right).

cut end electrode $(400 \mu \mathrm{V})$. This is primarily because the component of the center distance between the recording surfaces perpendicular to the fiber direction is $50 \mu \mathrm{m}$ in the side hole electrode and $25 \mu \mathrm{m}$ in the cut end electrode. It may also reflect that the side hole electrode can be moved close to the active fibers.

It is surprising that the medians of the amplitudes were 400 $800 \mu \mathrm{V}$, which is close to the maximal amplitudes predicted by the model and that amplitudes as high as $8 \mathrm{mV}$ could occur. To some extent the large amplitudes could be explained by assuming that they were recorded from fibers with diameters larger than $50 \mu \mathrm{m}$. According to the model, the amplitude of the action potentials increases with the square of the fiber diameter. In addition, the side hole electrode is an insulator except for the small recording surfaces and may thereby cause an increase in the electrical potential by as much as a factor of two (the "wall effect" [23]). The "wall effect" could not play a role when recording with the cut end electrode. To account for the large potentials an additional factor of two or more is needed. We therefore suggest that amplitudes predicted by the model are too low when the gap between muscle fiber and electrode is extremely narrow. The parameters for conductivity and anisotropy were chosen from measurements where the muscle tissue was assumed to be homogeneous. However, the muscle tissue is inhomogeneous and consists of insulating membranes in intra-and extracellular fluid with higher conductivity. The membrane currents flowing during depolarization of the muscle fiber are therefore forced to run in the narrow gaps of extracellular fluid [24]. The current density and thereby the potentials recorded by an electrode in the extracellular fluid immediately outside the fiber are therefore higher than predicted by the model.

In unipolar recording, Ekstedt [23] recorded up to $25 \mathrm{mV}$ with a single fiber multielectrode. The fact that the decline in amplitude for increasing distance between fiber and amplitude was steeper than predicted from the model (Fig. 10) when the maximal amplitude was larger than $10 \mathrm{mV}$ and fitted the theoretical curve for smaller amplitudes, supports the suggestion given above.

\section{Discussion}

From the model we have learned that when a bipolar electrode of small dimensions is oriented perpendicular to the direction of the muscle fibers only two to seven muscle fibers

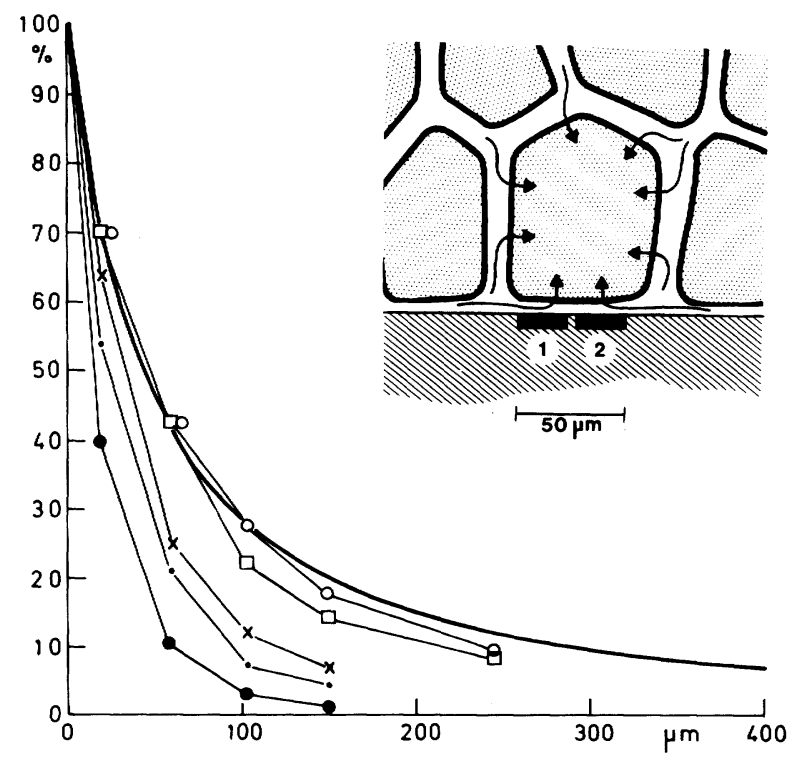

Fig. 10. To explain that the peak-to-peak amplitude recorded with bipolar electrodes can be two to three times greater than predicted by the model. Heavy line: decrease in peak-to-peak amplitude for increasing distance between the surface of the muscle fiber electrode as calculated for unipolar recording (see Fig. 3). The points on the thin lines are calculated from the peak-to-peak amplitudes determined by Ekstedt in experiments with a single-fiber multielectrode [23, Fig. 34]. The values are calculated for a $56 \mu \mathrm{m}$ muscle fiber, taking into account that the abscissa in Ekstedt's figure is distance along the multielectrode. The curves fit the model as long as the amplitudes are $8 \mathrm{mV}(\mathrm{O})$ and $10.7 \mathrm{mV}(\mathrm{D})$, and deviates for $12.5 \mathrm{mV}(\bullet), 18.2 \mathrm{mV}(\mathrm{X})$ and $24.5 \mathrm{mV}(\cdot)$ indicating that extraordinarily high amplitudes (12$25 \mathrm{mV}$ ) can be recorded from single fibers when the fiber is close to the electrode surface. If the gap between fiber and electrode is narrower than the gap between neighboring fibers the current density and thereby the potential in the extracellular fluid at the electrode is increased (as illustrated, upper right) beyond the values predicted from the model. The arrows indicate the current during depolarization.

are within the pick-up range of the electrode. This is in accordance with our experiments: action potentials from no more than two or three motor units were recorded up to $60 \%$ of maximal effort.

We have used a trifilar cut end electrode. The pair of recording surfaces perpendicular to the direction of the muscle fibers could be selected when the electrode was in situ. The tip of the wires formed a hook which fixed the electrode in the muscle. Once inserted the electrode could not be shifted to other motor units, and if withdrawn the track of damage acted as a 


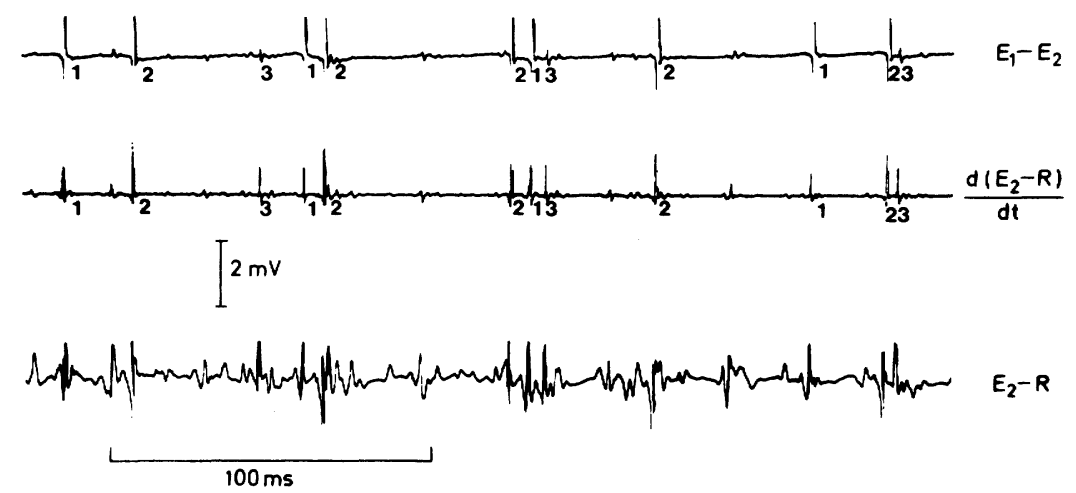

Fig. 11. Above: Selective recording of action potentials from two motor units 1 and 2 via a side hole electrode in the anterior tibial muscle of a normal subject at $20 \%$ of maximal effort. Middle: Action potentials from three motor units $(1,2$, and 3$)$ selected by differentiation of the lower trace: $d\left(E_{2}-R\right) / d t$. Note the similar shape of the potentials from motor units 1 and 3 . Below: Summated activity from many motor units recorded between one of the recording surfaces of the side hole electrode and a reference electrode $\left(E_{2}-R\right)$.

shunt and the selectivity was lost [1]. In patients with partial paralysis who could not recruit all motor units, we used an electrode with holes burnt into the side of the wires. The wires were passed in and out through skin and muscle. The side holes could thus be positioned close to active muscle fibers by gently pulling the ends of the wires at either side of the muscle [6].

Hannerz [5] was able to record action potentials from single motor units from threshold to maximal contraction with a selective wire electrode. It consisted of three silver wires with small holes burnt into the insulation. The best selectivity was obtained when the impedances of the holes were $4 \mathrm{M} \Omega$ and $200 \mathrm{k} \Omega$. The capacitance between the wire and the muscle tissue plus the capacitance of the input cable and amplifier is presumably above $40 \mathrm{pF}$. The recording surface with the $4 \mathrm{M} \Omega$ impedance will therefore act as a high-pass filter with cut-off frequency below $1 \mathrm{kHz}$. Calculations of the transfer function for the bipolar $(4 \mathrm{M} \Omega / 200 \mathrm{k} \Omega, 40 \mathrm{pF})$ electrode show that the common mode rejection of the electrode is low (approximately 1) and that the signal recorded by the electrode is almost identical to the signal recorded unipolarly by the $200 \mathrm{k} \Omega$ recording surface after a differentiation. As the model shows, the selectivity in unipolar recording is improved by high-pass filtering. The recording system used by Hannerz [5] has an upper frequency limit of $1 \mathrm{kHz}$. The total frequency range of the electrode and recording system is therefore equal to a band-pass filter around $1 \mathrm{kHz}$. This is below the frequency range where the $25 \%$ distances and thereby the pick-up ranges are small (cf. Fig. 5).

Recently the importance of high-pass filtering was emphasized by Gath and Stålberg [8] and Clamann and Lamb [7] . Clamann and Lamb [7] succeeded in extracting single motor unit action potentials by electronic differentiation of the signals picked up by small electrodes. The effect of differentiation of a unipolarly recorded trace is illustrated in Fig. 11. Action potentials from three motor units $(1,2$ and 3 in middle trace) were sorted out from an interference pattern (lower trace) by differentiation. The upper trace was recorded from the same site in the muscle via a side hole electrode. This recording is more selective; the amplitude of the action potentials of motor unit three being below the $25 \%$ limit relative to the amplitudes of motor units one and two. This illustrates the relative selectivity of a bipolar parallel and a bipolar perpendicular electrode. The signal recorded by a bipolar parallel electrode is, except for a proportionality factor, identical to the signal obtained by differentiation of a unipolarly recorded signal [25]. This is valid as long as the center distance between recording surfaces is below $100 \mu \mathrm{m}$.

The middle trace (Fig. 11) illustrates the error which may occur when single potentials are selected by narrowing the frequency band. The potentials from motor units one and three can no longer be distinguished by their amplitude and shape.

In conclusion, we can say that the best selectivity is obtained by recording via a small bipolar electrode, oriented perpendicular to the muscle fiber. Even then single unit recording at maximal effort is only possible when occasionally the electrode is positioned close to two or more fibers belonging to the same motor unit.

\section{APPENDIX}

The extracellular action potentials $\phi_{a n}(r, z)$ were computed by numerical integration of an intracellular action potential $V_{i}$ measured just under the membrane of a human muscle fiber [13] , [9] -[12] .

For a muscle fiber in an isotropic conductor the extracellular potential was calculated [9] from

$$
\phi_{e}(r, z)=\frac{a^{2} \sigma_{i}}{4 \sigma_{e}} \int_{-\infty}^{\infty} \frac{d^{2} V_{i} / d s^{2}}{\sqrt{r^{2}+(s-z)^{2}}} d s .
$$

$z$ and $r$ were distances along and perpendicular to the fiber axis respectively. $\sigma_{i}$ and $\sigma_{e}$ were the conductivities of the intracellular and the extracellular medium, $a$ the radius of the muscle fiber. The muscle tissue is an anisotropic conductor with larger conductivity $\sigma_{z}$ along the fiber than perpendicular to it $\sigma_{r}$. The extracellular potential for a muscle fiber in situ was therefore calculated [9] from 


$$
\phi_{a n}(r, z)=\frac{a^{2} \sigma_{i}}{4 \sigma_{e}} \cdot K(z) \cdot \int_{-\infty}^{\infty} \frac{d^{2} V_{i} / d s^{2}}{\sqrt{r^{2}\left(\sigma_{z} / \sigma_{r}\right)+(s-z)^{2}}} d s
$$

where

$$
\phi_{e}=\sqrt{\sigma_{r} \cdot \sigma_{z}}
$$

and

$$
K(z)=\frac{\delta \phi_{e}(a, z)}{\delta r} \frac{\delta \phi_{e}\left(a \cdot \sqrt{\sigma_{z} / \sigma_{r}}, z\right)}{\delta r} .
$$

The assumptions were:

i) radius of the muscle fiber: $a=28 \mu \mathrm{m}$

ii) conduction velocity: $4 \mathrm{~m} / \mathrm{s}$

iii) ratio between intracellular and extracellular conductivity $\sigma_{i} / \sigma_{e}=1 / 3$

iv) Anisotropy: $\sigma_{z} / \sigma_{r}=2.8$

v) $K(z) \cong 1.7$ for $\sigma_{z} / \sigma_{r} \cong 2.8[9]$

vi) distance between the centers of the recording surfaces of the bipolar electrodes: $25 \mu \mathrm{m}$.

\section{REFERENCES}

[1] R. Bigland and O. C. J. Lippold, "Motor unit activity in the voluntary contraction of human muscle," J. Physiol. (Lond.), vol. 125, pp. 322-335, 1954.

[2] H. Norris and E. L. Gasteiger, "Action potentials of single motor units in normal muscle," Electroenceph. clin. Neurophysiol., vol. 7, pp. 115-126, 1955.

[3] J. D. Gillies, "Motor unit discharge patterns during isometric contraction in man," Proc. Physiol. Soc., 18-19 February 1972, J. Physiol., vol. 223, pp. 36-37, 1972.

[4] E. Stallberg and B. Thiele, "Discharge pattern of motoneurones in humans. A single-fiber EMG study," In: New Developments in Electromyography and Clinical Neurophysiology, ed. J. E. Desmedt, vol. 3, pp. 234-241, Karger, Basel, 1973.

[5] J. Hannerz, "An electrode for recording single motor unit activity during strong muscle contractions," Electroenceph. clin. Neurophysiol., vol. 37, pp. 179-181, 1974a.

[6] J. E. Desmedt and E. Godaux, "Vibration-induced discharge patterns of single motor units in the masseter muscle in man," $J$. Physiol. (Lond.), vol. 253, pp. 429-442, 1975.

[7] H. P. Clamann and R. L. Lamb, "A simple circuit for filtering single unit action potentials from electrograms," Physiol. \& Behav., vol. 17, pp. 149-151, 1976.

[8] I. Gath and E. V. Stålberg, "Techniques for improving the selectivity of electromyographic recordings," IEEE Trans. Biomed. Engng., BME vol. 23, pp. 467-472, 1976.

[9] P. Rosenfalck, "Intra- and extracellular potentials fields of active nerve and muscle fibers," Acta physiol. Scand., vol. 75, suppl. 321, pp. 1-168, 1969.

[10] P. Rosenfalck, "Relationship between intracellular and extracellular action potentials of striated muscle fibers," 5th International Biophysics Congress, 1975 , abstract 35.

[11] P. Rosenfalck, "Power spectra of simulated action potentials of a muscle fiber in an anisotropic volume conductor," XV Scandinavian Congress of Physiology and Pharmacology, Aarhus, Acta physiol. Scand., suppl. 440, p. 319, 1976a.

[12] P. Rosenfalck, "Lidt biologisk elektrofysik (Volumenlederteori)," Fysisk Tidsskrift, vol. 74, pp. 1-20, 1976b.

[13] H. P. Ludin, "Microelectrode study of normal human skeletal muscle," Europ. Neurol., vol. 2, pp. 340-347, 1969.
[14] J. Ekstedt and E. Stålberg, "How the size of the needle electrode leading-off surface influences the shape of the single muscle fiber action potential in electromyography," Comp. Prog. Biomed., vol. 3, pp. 204-212, 1973.

[15] E. Kugelberg, Patent no. 87565 (Sweden), 1936.

[16] J. Hannerz, "Discharge properties of motor units in relation to recruitment order in voluntary contraction," Acta physiol. Scand., vol. 91, pp. 374-384, 1974.

[17] J. V. Basmajian, W. J. Forrest and G. Shine, "A simple connector for fine-wire electrodes," J. appl. Physiol., vol. 21, pp. 1680, 1966.

[18] P. Rosenfalck and F. Buchthal, "On the concept of the motor subunit," Int. J. Neurosci., vol. 1, pp. 27-37, 1970.

[19] F. Buchthal and P. Rosenfalck, "On the structure of motor units," In: New Developments in Electromyography and Clinical Neurophysiology, ed. J. E. Desmedt, vol. 1, pp. 71-85, Karger, Basel, 1973.

[20] M. E. Brandstater and E. H. Lambert, "Motor unit anatomy," In: New Developments in Electromyography and Clinical Neurophysiology, ed. J. E. Desmedt, vol. 1, pp. 15-22, Karger, Basel, 1973.

[21] A. M. Doyle and R. F. Mayer, "Studies of the motor unit in the cat. A preliminary report," Bull. Sch. Med. Maryland, vol. 54, pp. 11-17, 1969.

[22] E. Stålberg, M. S. Schwartz, B. Thiele and H. H. Schiller, "The normal motor unit in man. A single fiber EMG multielectrode investigation," J. Neurol. Sci., vol. 26, pp. 291-301, 1976.

[23] J. Ekstedt, "Human single muscle fiber action potentials," Acta physiol. Scand., vol. 61, suppl. 226, pp. 1-96, 1964.

[24] F. Buchthal, C. Guld and P. Rosenfalck, "Innervation zone and propagation velocity in human muscle," Acta physiol. Scand., vol. 35, pp. 174-190, 1955.

[25] V. Pollack, "The wave shape of action potentials recorded with different types of electromyographic needles," Med. Biol. Eng., vol. 9, pp. 657-664, 1971.

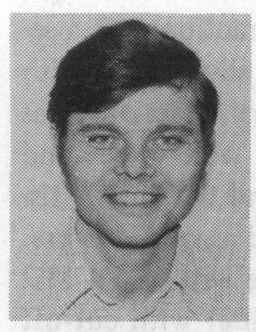

Steen Andreassen was born in Copenhagen in 1949. He received the M.S. degree in Electrical Engineering in 1973 from The Technical University of Denmark. His Ph.D. work on "The interval pattern of single motor units" was done at the Institute of Neurophysiology, University of Copenhagen and the Electronics Laboratory, The Technical University of Denmark. In 1975 he was co-founder of "Danish Data Electronics, ApS," a firm active in the fields of computer aided design and in microcomputer applications. In 1977 he was on a one year visit at the Laboratory of Professor R. B. Stein, Department of Physiology, University of Alberta, pursuing his interests in the neurophysiology of the motor system and in signal processing of biological data. Currently he is with the Institute of Electronic Systems, Aalborg University Centre, Denmark.

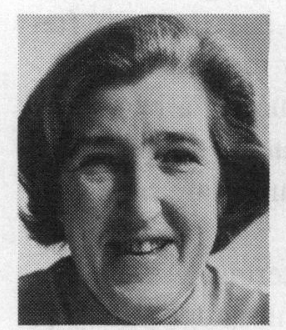

Annelise Rosenfalck was born in Denmark in 1922 and received her MSc in electronic engineering from the Technical University of Denmark in 1947. Since then she has mainly worked at the Institute of Neurophysiology, University of Copenhagen. In February 1978 she was appointed professor of Medical Electronics at the Institute of Electronic Systems, Aalborg University Centre, Denmark, a new University with a goal of interdisciplinary collaboration. 